\title{
Analysis of Temporal Characteristics of Burglary Crime
}

\author{
Dong Cai ${ }^{1,2,}$, Zimiao Shi ${ }^{1}$ \\ ${ }^{1}$ Public Security Management Department, Jiangsu Police Institute, Nanjing, Jiangsu, China \\ ${ }^{2}$ Key Laboratory of Police Geographic Information Technology, Ministry of Public Security, Changzhou, \\ Jiangsu, China \\ *Corresponding Author.
}

\begin{abstract}
Social security order had generally stabilized, and various major criminal crimes had been effectively controlled, but the problem of burglary crime was very serious. Burglary crime had gradually shown the different characteristics from the past, making it increasingly difficult to control. Data of Burglary crime from 2015 to 2019 in Danyang City, Jiangsu Province, was collected. The main contents of the study included temporal trend analysis based on time series, temporal hotspot analysis based on Biharmonic Spline Surface Interpolation, and temporal correction analysis based on Time Period Probability. Characteristics of burglary cases in yearly scale, monthly scale, and daily scale were extracted in this paper. This study found that the burglary cases in Danyang showed different temporal distributions on different time scales. This study further enriched the spatio-temporal analysis methods of burglary crime, and put forward targeted and reliable suggestions for police departments.
\end{abstract}

Keywords:Temporal Characteristics Analysis,Biharmonic Spline Surface Interpolation, Time Period Probability Analysis, Burglary Crime,Danyang City

\section{Introduction}

\subsection{Research background}

In recent years, all over the country had launched special treatments against burglary crime. At the same time, the crime of burglary was showing the new characteristics. The difficulty of case investigation was greatly increased, and the situation of Crime attack and prevention was still very severe [1-3].

Since the beginning of the new century, the research of criminal geography in China was in the ascendant, and many scholars had deepened and innovated on the basis of the relevant theories of foreign criminal geography[4-5]. In this period, the idea of "data empowerment" has been widely promoted in police departments. Under the unified leadership of the Public Security Ministry of China, the Jindun Project had been effectively promoted, the police geographic information system had been continuously improved. Modern urban social security management means were more abundant, and crime attack and prevention means were more diverse. Many new theories and new technologies made it possible to study the crime of burglary systematically and deeply.

\subsection{Research Significance}

In this paper, an improved Temporal Characteristics analysis method of burglary was proposed. The main contents of the study included temporal trend analysis in yearly scale based on time series, temporal hotspot analysis in monthly scale based on Biharmonic Spline Surface Interpolation, and temporal correction analysis in daily scale based on Time Period Probability.

Based on the data of burglary in Danyang City from 2015 to 2019, this paper systematically analyzed the time distribution of burglary cases in Danyang City, and puts forward some countermeasures from the aspects of informatization, refinement and efficiency. The purpose of the research was to help the police department to 
scientifically allocate police resources and reduce burglary cases as much as possible. The research process also provided a model case for local police departments to analyze the situation of burglary.

\subsection{Review of current research}

From the 19th century to the present, the research on the temporal and spatial analysis of crime has gone through three stages: Cartographic school, Chicago school and modern criminal geography. Scholars of different schools have made various researches on the temporal and spatial distribution of crime from their own perspectives and put forward corresponding theories. Going through the baptism of time, Social Disintegration Theory, Daily Activities Theory, of Rational Choice Theory and Environmental Criminology Theory stood out from many theories and become the mainstream theories of criminal geographical analysis [6].

The principle of environmental criminology theory came from the theoretical research results of Chicago school from 1920s to 1930s, which mainly included three theories: Defense Space Theory, broken window theory and defense environment design theory. The theory emphasized that the occurrence of criminal behavior was affected by the natural environment, built place, time and other opportunity factors, only when the offender and the potential victim appeared in the same place at the same time, the crime would occur. It was advocated to improve the micro environment to prevent crime [7].

Domestic research on time and space of crime began in the 1980s, mainly introducing foreign criminology and criminal geography theories. Xiaoguang Zhu, Fazeng Wang and others introduced the geography of crime, the spatial distribution of crime and the means of prevention and control [8-10]. With the further development of criminology theory, domestic scholars had redefined "criminal geography" as "environmental criminology", which became the fundamental theory of Intelligence Oriented Policing mode.

Since the beginning of the new century, scholars had made empirical analysis based on the existing theories and crime data of various places. The patterns of crime spatial-temporal distribution were discovered by multiple theories[11-14]. The related research of criminology was experiencing a rapid development period in the ascendant. There were many research on multi-disciplinary integration, multi-level scale and countermeasures. Although the basic criminal information was still not easy to obtain due to secret related, with the rapid development of economy and society, crime and its associated social problems would inevitably cause more attention. Moreover, some local governments provided scholars with unclassified data in the form of "disclosure by application". Therefore, the research of crime geography had a very large development space in the future.

\section{Data Preprocessing}

The data of criminal cases used in the study mainly came from the Public Security Bureau of Danyang City. Economic statistics were mainly from Danyang Statistics Bureau and open street map (OSM).

\subsection{Data Cleaning}

This paper carefully combed the data of burglary cases in Danyang City from 2015 to 2019 derived from the public security criminal case database platform, corrected the format errors of individual data records, and removed invalid data such as case withdrawal and duplicate records. All kinds of POI data in OSM were confirmed to be valid.

\subsection{Removal of Confidential Information}

The data of burglary cases in Danyang City from 2015 to 2019 derived from the public security criminal case database platform had been processed. The privacy information such as the victim's name, ID card number and mobile phone number was deleted. The information needed for the research, such as case number, amount involved, time of the crime and location of the crime, was retained. 


\section{Key Technology}

\subsection{Temporal Hotspot Analysis}

Temporal hotspot analysis based on Biharmonic Spline Surface Interpolation was studied. The monthly and weekly crime data were imported respectively, and the scattered data were interpolated by Biharmonic Spline to produce the surface formed by the linear combination of Green function centered on each data point. This method had no requirements on the number and distribution of control points[15-17].

Algorithm of Biharmonic Spline Surface Interpolation was as follows:

$P_{i}(\mathrm{i}=1 \sim \mathrm{N})$ was scattered control points in m-dimensional space. The problem of Biharmonic Spline Surface Interpolation was transformed into the solution of equations (1):

$$
\begin{aligned}
\nabla^{4} w(P) & =\sum_{i=1}^{N} a_{j} \delta\left(P-P_{j}\right) \\
w\left(P_{i}\right) & =w_{i}
\end{aligned}
$$

In above equations, $\nabla^{4}$ was operator of Biharmonic, $\delta(P)$ was unit-impu lse function, $P$ was one position in m-dimensional space, $w(P)$ was the value at position $P$.

Ordinary solution of equations was:

$$
w(P)=\sum_{j=1}^{N} a_{j} \varphi_{m}\left(P-P_{j}\right)
$$

Where the coefficient $a_{j}$ satisfied the following linear equation:

$$
w_{i}=\sum_{j=1}^{N} a_{j} \varphi_{m}\left(P_{i}-P_{j}\right)(3)
$$

In above equation, $\varphi_{m}(P)$ was Green Function in m-dimensional space, as shown in the table 1 .

\section{Table 1 Green Function in m-dimensional space}

\begin{tabular}{cc}
\hline Number of Dimensional & Green Function: $\varphi_{\mathrm{m}}(\mathrm{P})$ \\
\hline \multicolumn{1}{c}{1} & $|P|^{3}$ \\
2 & $|P|^{2}(\ln |P|-1)$ \\
3 & $|P|$ \\
5 & $\ln |P|$ \\
$m \geq 6$ & $|P|^{-1}$ \\
\hline
\end{tabular}

\subsection{Time Period Probability Analysis}

In consideration that the alarm time was not consistent with the time of the case happening, the probability method was used in Time Period Probability Analysis to revise the time of the cases. The time resolution would be more delicate, which could reveal the time distribution of burglary from am 0 to 7.

ISSN: 0010-8189 
The specific analysis steps were as follow:

Interval statistics of burglary cases. Suppose the total number of cases is $n$, the starting time of cases is $s_{i}$, and the ending time is $f_{i}, i \in 1 \ldots n$. For every case, $t_{d}$ was the time interval between the start time and the end time: $t_{d}=f_{i}-s_{i}$.

2)The starting point of the interval was the period where the start time was located, and the end point was the period where the end time was located. Each period in the interval was assigned with a corresponding probability value: $p=\frac{1}{f_{i}-s_{i}}$. The probability value of the case occurrence in each period was summed. Finally, the time period probability distribution of criminal activities was obtained and plotted.

Time Period Probability Analysis could play a good role in reducing the peak. The time resolution of the original data was improved to a great extent, and the crime time accuracy of confused victims was also improved. From the perspective of probability, the burglary cases time of confused victims could be effectively dispersed from0:00 to 7:00.

\section{Research Process of Temporal Characteristics Analysis}

\subsection{Temporal Trend Analysis Based on Time Series}

Temporal trend of burglary case quantity was analyzed, as shown in Figure 1-3.

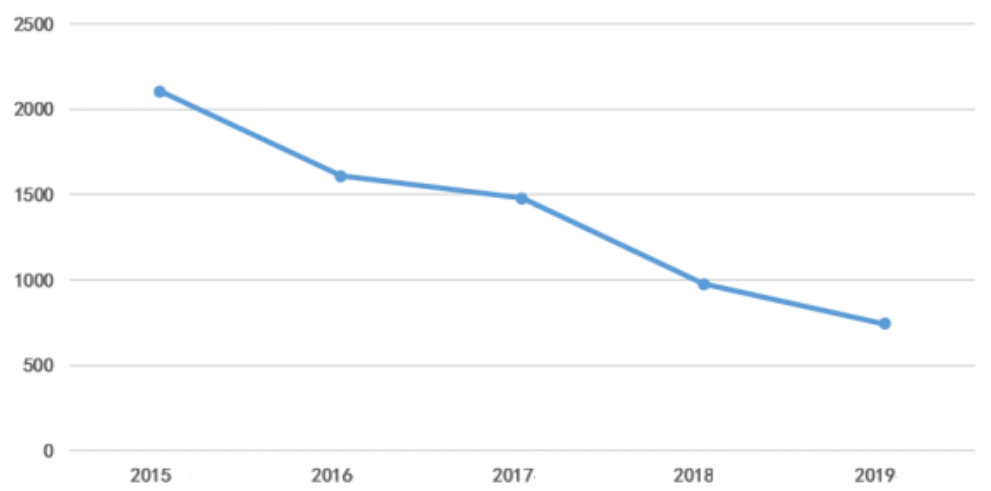

Fig 1: Trend Chart of Annual Burglary Cases in Danyang City

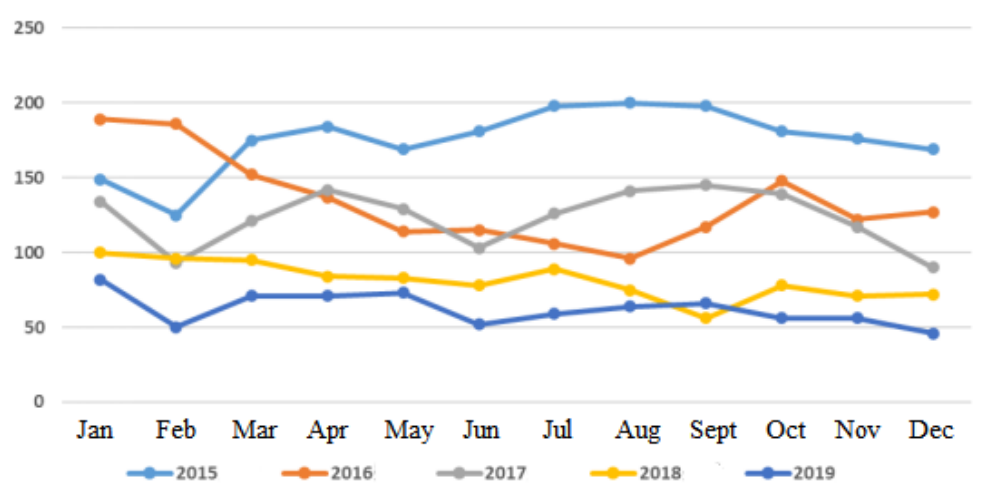

Fig 2: Trend Chart of Monthly Burglary Cases in Danyang City 
CONVERTER MAGAZINE

Volume 2021, No. 5

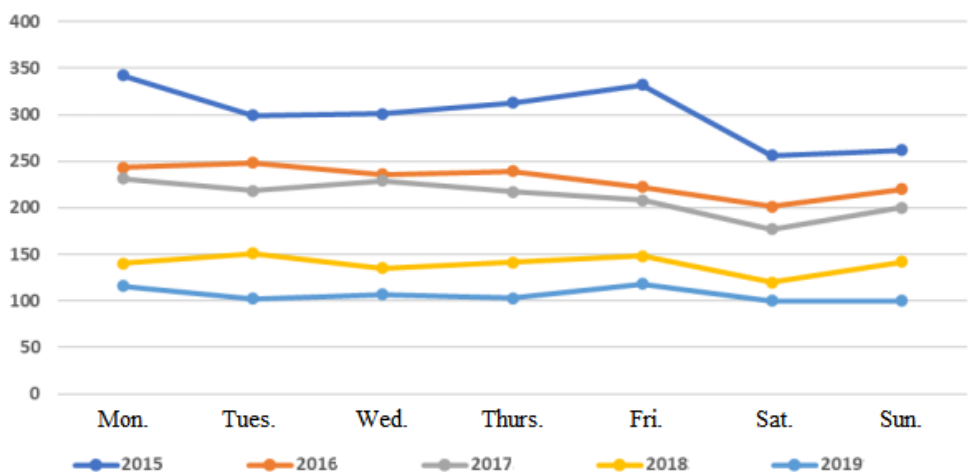

Fig 3: Trend Chart of Weekly Burglary Cases in Danyang City

4.2 Temporal Hotspot Analysis Based on Biharmonic Spline Surface Interpolation

Biharmonic Spline Surface Interpolation method was used to analyze the monthly and weekly temporal hotspot of burglary crime, as shown in figures 4-5. The x-axis represented "month", the y-axis represented "week", and the z-axis represented "quantity of burglary crime".

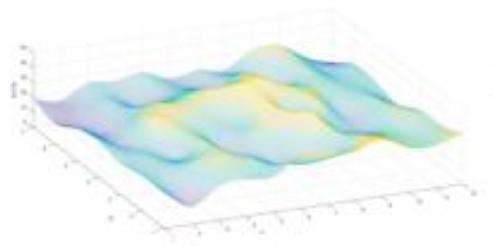

(a) 2015

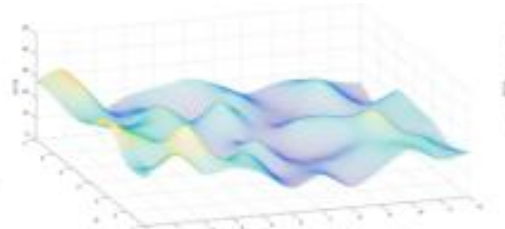

(b) 2016

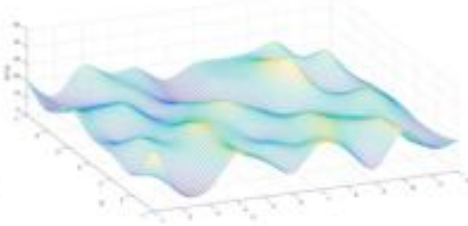

(c) 2017

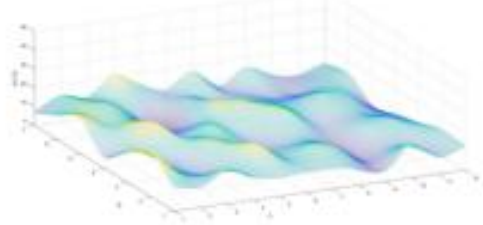

(d) 2018

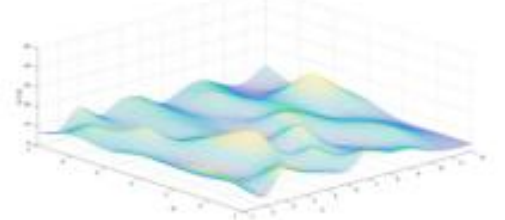

(e) 2019

Fig 4: Temporal Hotspot Distribution of Burglary Crime

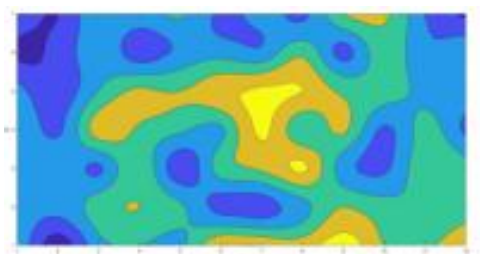

(a) 2015

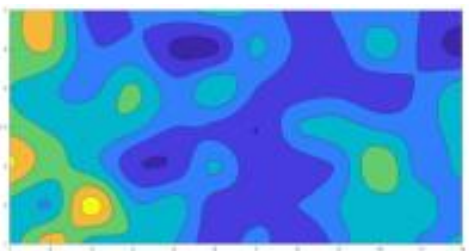

(b) 2016

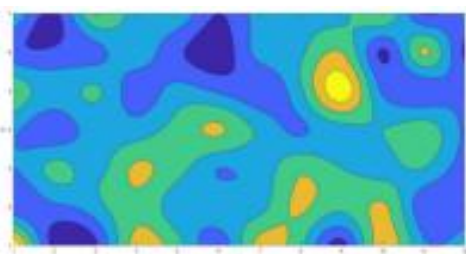

(c) 2017

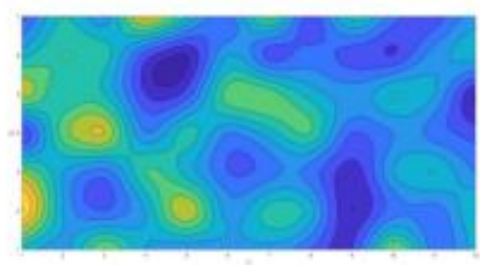

(d) 2018

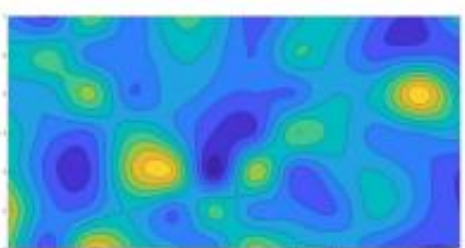

(e) 2019

Fig 5: Temporal Hotspot Contour Map of Burglary Crime

ISSN: 0010-8189 


\subsection{Temporal Correction Analysis Based on Time Period Probability}

Firstly, Statistics of burglary crime time period in Danyang City was shown as Figure 6:

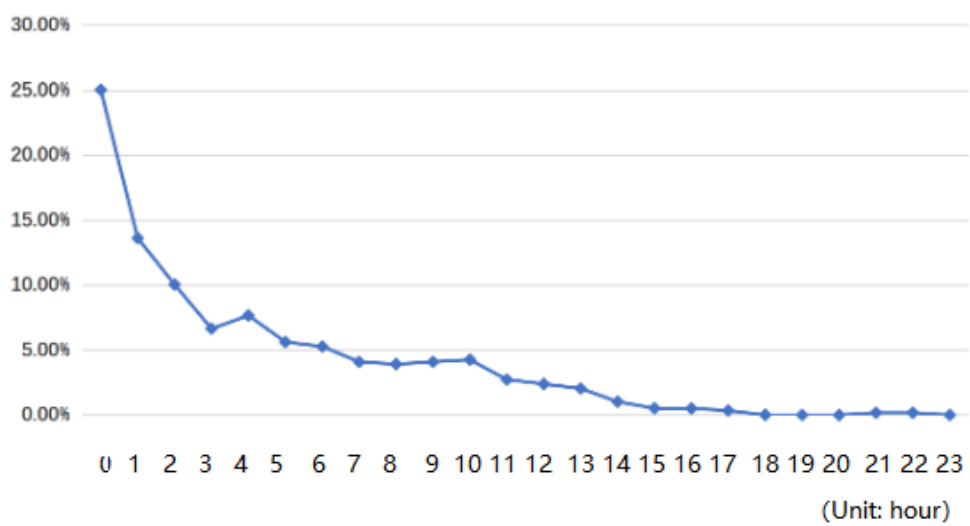

Fig 6: Statistics of burglary cases in Danyang City

Then, according to the interval of cases, the probability of each case in the corresponding time was calculated and summed, and the temporal distribution of cases was obtained after the correction of Time Period Probability analysis method as shown in Figure 7.

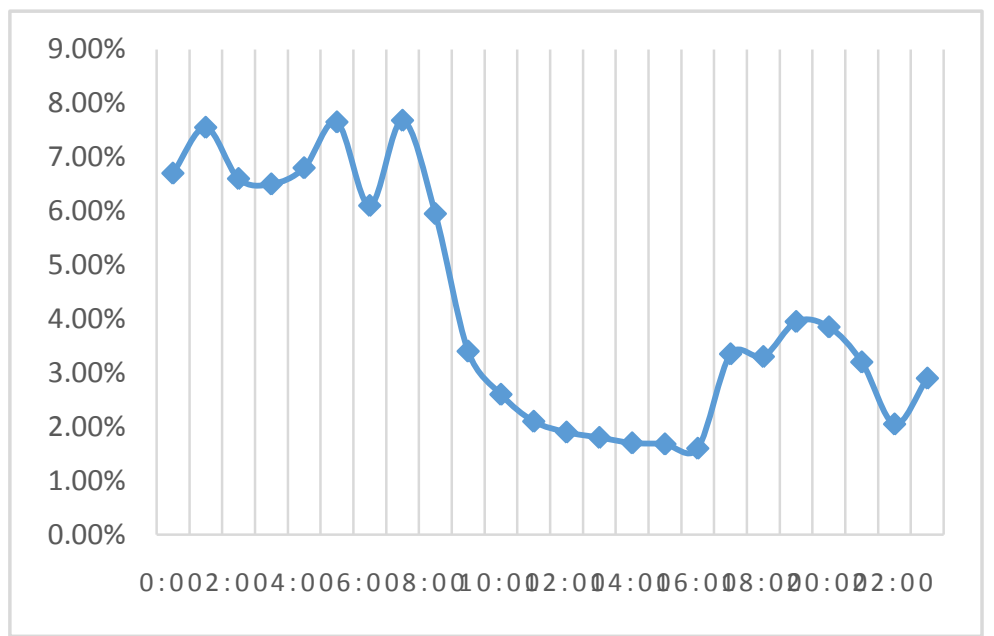

Fig 7: Statistics of burglary cases based on Temporal Correction Analysis

\section{Discussion on Results of Temporal Characteristics Analysis}

5.1 Analysis of experimental results of Temporal Trend Analysis

\subsubsection{Pattern of Annual Quantity of Burglar Crime}

According to Figure 1, it could be found that the burglary cases were declining year by year. The quantity of burglary cases in Danyang City decreased the largest in 2015-2016, and the quantity of burglary cases in Danyang City was the lowest in 2016-2017. The decrease of the number of cases year by year reflected the achievements of special remediation by police departments, and also showed the government's social governance ability.

5.1.2 Pattern of Monthly Quantity of Burglar Crime

According to Figure 2, it could be found that the quantity of burglary cases in spring was the largest, accounting for $26.02 \%$ of the whole year. The quantity of burglary cases in summer, autumn and winter was roughly the same,

ISSN: 0010-8189 
accounting for $24.33 \%, 24.95 \%$ and $24.69 \%$ of the whole year respectively; In a single month, the quantity of cases in January, March, April and October was the highest, while the quantity in February, June and December was the lowest.

In February, the Spring Festival transportation was coming to an end, and migrant workers were returning home for the Spring Festival, which greatly enhanced the protection of families, so the quantity of burglar cases was low; June is the summer vacation period. students who went out to study went home back for vacation. The time when there were people in the residence was longer, which increased the risk of criminals. Therefore, the quantity of burglar cases in this period was low. March, April and October were the months after the end of winter vacation and summer vacation. At this time, migrant workers and students go out to work and study, and the vacant time of residence increased, so the quantity of burglar cases was large; January was a special transition period between two years, and it was also the preparing period for the Spring Festival. More mobility of personnel brought to greater instability and relatively poor social security. This result expounded the relationship between people's daily activities and the number of burglar crime.

\subsubsection{Pattern of Weekly Quantity of Burglar Crime}

According to Figure 3, it could be found that the quantity of burglary cases during working days in a week was relatively stable, while the quantity of burglary cases on Saturdays and Sundays decreases, showing the characteristics of "more in working days, less in weekends". The largest number of burglary cases appeared on Mondays, and the least number appeared on Saturdays.

The above results reflected the influence of people's daily activities on the quantity of burglary crime: during working days (Monday to Friday), office workers needed to go out for work, leaving their apartments unattended, which stimulated burglars to commit crimes. Saturdays and Sundays were vacation time. On the one hand, office workers had a rest at home. On the other hand, children doesn't have to go to school, which enhanced their ability to monitor the apartments and made their apartments in a state of being cared for. Therefore, the quantity of burglary cases was relatively lower.

\subsection{Analysis of experimental results of Temporal Hotspot Analysis}

According to Figure 4-5, there were three stable temporal hotspots of burglary crime. That was Friday in March, Tuesday in April and Wednesday in May. Howerer, the reason for the temporal hotspots was not clear, it was highly consistent with a thesis conclusion of People's Public Security University of China, 2019. The title of the master's thesis was Spatial-Temporal Hotspot Analysis and Prevention and countermeasures of Theft Crime.

\subsection{Analysis of experimental results of Temporal Correction Analysis}

According to Figure 6, we found that there were four peaks of burglary cases in a day, which were 1:00-2:00, 5:00-6:00, 7:00-8:00 and 19:00-20:00.

First of all, the peaks at 1:00-2:0 and 5:00-6:0 could be explained from the "Sleeping Cycle Theory". The so-called "sleep cycle" referred to people's normal sleep structure cycle, which is divided into two phases: Non Rapid Eye Movement(NREM) sleep and Rapid Eye Movement(REM) sleep [18]. NREM sleep and REM sleep alternate, alternate once called a sleep cycle. Two kinds of sleep happened in circles. There were 4-5 sleep cycles each night, and each cycle continued 90-110 minutes. Usually, people turned off their lights at 21:00 and 22:00, and began to enter the sleep cycle at about 23:00. At 1:00 a.m., most people were already in the REM sleep period of the first sleep cycle. This was the deepest sleep, for that it was more difficult to detect the burglary crime. Similarly, at 5:00 a.m., people were in the fourth sleep cycle of REM sleep, it was also difficult to detect the occurrence of illegal behavior. The second peak was appearing. 
Secondly, for the peak of burglary cases at 7:00-8:00 a.m., it should be caused by the basic principle of Time Period Probability method. Although the "early peak" of the original data during 7:00-8:00 a.m. had been evenly cut, it still could reflect the probability of burglary cases during 7:00-8:00 a.m. truly.

Finally, at the peak of 19:00-20:00 p.m., most people went out for a walk, chat or other recreational activities after dinner. There was no guard at home, so that burglars had more chances to commit burglary crime.

\section{Control and Prevention of Burglary Crime}

(1) Informationize of Crime Management base on burglary analysis system

The crime of burglary is often affected by many factors, such as nature, humanity, economy and so on. From the perspective of actual combat, combined with the thinking of big data, we can analyze the basic police data with long time span, large sample size and high spatial-temporal resolution, take the analysis results of the terminal as the starting point to recognize the spatial-temporal distribution of burglary cases, and reverse explore the occurrence mechanism-inhibition mechanism of burglary cases. In this way, we need to establish a real-time, detailed, comprehensive and reliable mechanism for data collection, analysis and judgment, regularly analyze and study the spatial and temporal distribution of burglary crime in the region, provide timely and targeted countermeasures, continuously enhance the effectiveness of data oriented and intelligence oriented mechanism in actual police combat, and constantly improve the level of police modernization. So that police deployment could be more targeted and tactical effect could be more prominent.

First of all, the research and judgment center should collect, clean and comb the data of recent burglary cases in the jurisdiction, identify the temporal and spatial hot spot patterns of crimes through the analysis system, and formulate the corresponding patrol scheme according to the results. Secondly, the new standardized data should be added to the historical database of the occurrence inhibition mechanism analysis of indoor theft cases, so as to increase the sample size and improve the reliability and comprehensiveness of the analysis data, so as to explore the deep-seated occurrence-inhibition mechanism of indoor theft cases, and provide a more scientific theoretical basis for the attack and prevention and control of indoor theft in a longer period of time in the future. Finally, real-time analysis of the existing crime data should be carried out at different stages of the implementation of the strike prevention and control program to track and verify the implementation effect of the current patrol scheme, and timely adjust according to the feedback results.

ISSN: 0010-8189 


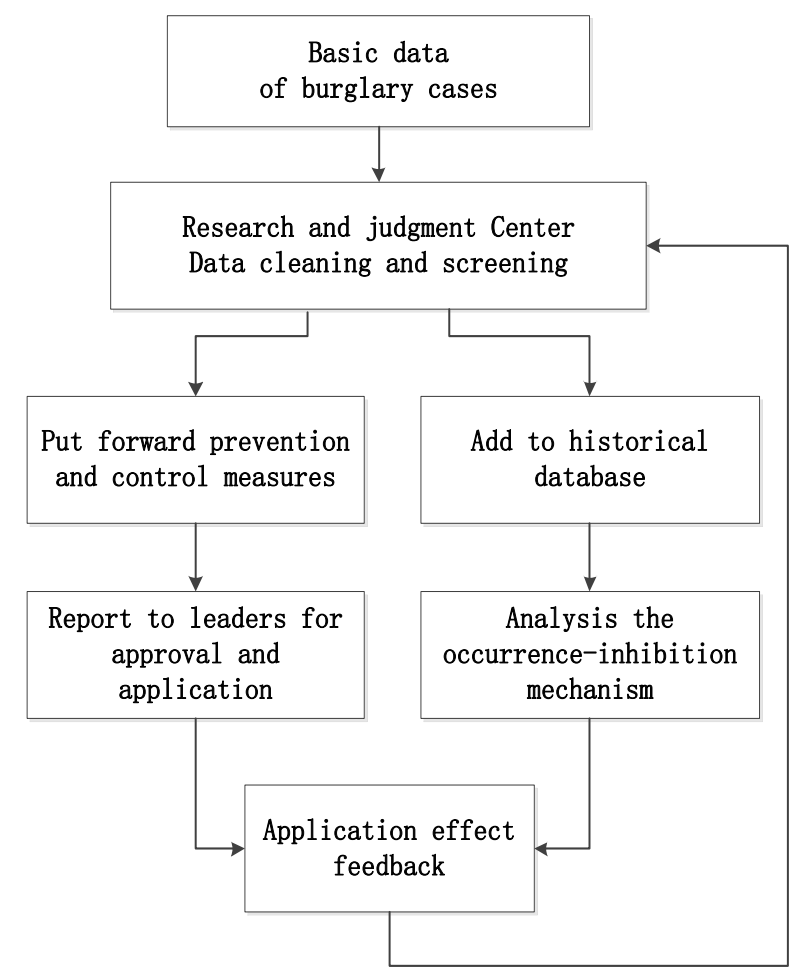

Fig 8: Work Process Flow of Research and Judgment Center

(2)Efficient security patrol and reasonable police deployment in temporal hotpot

It can be found from this study that the burglary cases in Danyang City mostly occur at 2:00, 10:00 and 14:00 in a day. It is true that at present, there are corresponding patrol forces in every district, community and police station, but most of these patrols are implemented without targeted patrol. The pattern of spatial and temporal distribution of crimes has not be discovered, which leads to inefficient patrol. Inefficient patrol cannot effectively deter burglars, but also increases the workload of the police. It results in a great waste of police resources. This has resulted in a great waste of police resources.

Therefore, according to the research results, the intensity and density of police patrol should be strengthened in spring (March, April and may), from 6:00 to 9:00, from 11:00 to 14:00 and from 22:00 to 24:00 every day. At the same time, more attention should be paid to Friday in March, Tuesday in April and Wednesday in May. Police and community group defense organization could be organized to patrol in the corresponding period of time. Slow patrol methods such as walking patrol and bicycle patrol should be used as patrol mode. Eye catching signs and lights are required. It is suggested to reduce the income of crime by increasing the risk of crime, so as to reduce the occurrence of burglary crime.

\section{Conclusion and Prospect}

\subsection{Research Conclusion}

Taking Danyang City of Jiangsu Province as the research area, aiming at the problems existing in the fight against and prevention of domestic burglary cases, this paper studied the temporal characteristics of burglary crime in Danyang City based on theories and methods of crime spatial-temporal hotspot. The data of burglary cases in Danyang City from 2015 to 2019 was used in the research.

Time series analysis, Biharmonic Spline Surface Interpolation and Time Period Probability were used to analysis 
temporal characteristics of burglary crime. It was found that burglary crime has significant time aggregation in Annual scale and monthly scale.

This paper proposed a comprehensive analysis method of temporal characteristics of burglary crime based on the previous studies on environmental criminology. In view of the above, it put forward some corresponding governance suggestions according to the experimental conclusion, and provided assistant decision making for the prevention and control of burglary Crime for Police department based on the temporal characteristics.

\subsection{Research Prospect}

As burglary cases at night often occurred in the victim's unconsciousness, the specific time of the crime was difficult to confirm. Time Period Probability Method was introduced to the crime time correction of alarm platform.

But the essence of this method is only the distribution and superposition of probability. How to get the exact time of burglary at night still needs further research.This method could only reflect the distribution and superposition of probability. How to get the exact time of burglary cases at night still needed further study.

\section{Acknowledgements}

This work was financially supported by the Blue Project of Jiangsu Universities, Theory and Soft Science Project of Ministry of Public Security No. 2018LLYJJSST053, Green Seedling Project of JSPI No. JSPI2018QM, Research and Innovation Team Project of JSPI, and the Natural Science Project of JSPI No. 2017SJYZZ01.

\section{References}

[1] Z.Wen,"Prevention and Control Countermeasure on Robbery Forcible Seizure and Larceny," Hunan University, 2009.

[2] Z. Hai, Y. Han, "A review of the research progress of crime hot spots," Criminal Research, no.6, pp. 102-110, 2014.

[3] J.X. Zhu, "Spatio-Temporal Analysis and Research on Prevention and Control Measures Based on Crime hot spots_- Taking Robbery Cases in the Six Districts of B City as an Example," People's Public Security University of China, 2019.

[4] P. Chen, W. Ma, "Application of hierarchical clustering method in hot spot analysis of space crime,’Journal of Chinese People's Public Security University(Science and Technology), vol. 19, no.1, pp. 64-67, 2013

[5] Z.H. Ren, Z. H. Zhang, W. Liu, Z.Y.Guo, "Detecting spatio temporal hot spots for vehicle thefts by multi-scale analyses,” Journal of East China Normal University(Natural Science),vol. 3, pp. 136-145, 2018.

[6] Z.W. Tang, "Spatial-Temporal Hotspot Analysis and Prevention and countermeasures of Theft Crime," People's Public Security University of China, 2019.

[7] W. Wang, "Research on the Construction of Social Crime Prevention and Control System--A Case Study on the Social Crime Prevention and Control Work of H City," Zhejiang Gongshang University, 2018.

[8] X.G. Zhu, “Introduction of Criminal Geography,'Human Geography, no.2, pp. 40-46, 1989.

[9] F.Z. Wang, "A Review of Urban Spatial Anti-Crime Study in China from 1980 to 2000," Human Geography, vol. 25, no.4, pp. 25-30, 2010.

[10] F.Z. Wang, “The Spatial Anti-Urban Crime,” Journal of Henan University(Natural Science), vol. 42, no.5, pp. 563-570, 2012.

[11] L.B. Moses, J.Chan, "Algorithmic prediction in policing: assumptions, evaluation and accountability,’Policing and Society, vol. 28,no.7, pp. 806-822, 2018.

[12] G. Rosser, T. Davies, K.J. Bowers, et al.,"Predictive crime mapping: Arbitrary grids or street networks?" 
Journal of Quantitative Criminology, vol. 33, no.3, pp. 569-594, 2017.

[13] X.F. Yang,“Criminological theoretical basis and practical evaluation of hot spot policing," Journal of People's Public Security University of China(Social Sciences Edition), no.3, pp. 33-39, 2018.

[14] L.Liu, Y.H.Wu, G.W.Song, et al.,"Research progress on policing strategy of crime prevention and the evaluation of its effectiveness in space and time," Journal of Geo-information Science, vol. 23, no.1, pp. 29-42, 2021.

[15] M.Rosenblatt,"Remarks on some nonparametric estimates of a density function," The Annals of Mathematical Statistics,vol. 27, no.03, pp. 95-100, 1956.

[16] E.Pahzkn,“On Estimation of a Probability Density Function and Mode,’TheAnnals of Mathematical Statistics,vol. 33,no.3, pp. 1065-1076,1962

[17] M.West,“Kernel density estimation and marginalization consistency. Biometrika, vol. 78, no.2, pp. 421-425, 1991.

[18] B. Christine, C. Christian. "'Sleep Cycles' package for R - A free software tool for the detection of sleep cycles from sleep staging,"Methods X, pp. 1-9, 2021 